\title{
Palliative and end-of-life care for heart failure patients in an aging society
}

\author{
Takahiro Okumura, Akinori Sawamura, and Toyoaki Murohara
}

Department of Cardiology, Nagoya University Graduate School of Medicine, Nagoya, Japan

Received: March 16, 2018 Accepted: March 22, 2018

\section{Correspondence to}

Takahiro Okumura, M.D. Department of Cardiology, Nagoya University Graduate School of Medicine, 65

Tsurumai-cho, Showa-ku,

Nagoya 466-8550, Japan

Tel: +81-52-744-2147

Fax: +81-52-744-2210

E-mail: takaoku@med.nagoya-u.ac.jp
The populations of Asian countries are expected to age rapidly in the near future, with a dramatic increase in the number of heart failure (HF) patients also anticipated. The need for palliative and end-of-life care for elderly patients with advanced $\mathrm{HF}$ is currently recognized in aging societies. However, palliative care and active treatment for HF are not mutually exclusive, and palliative care should be provided to reduce suffering occurring at any stage of symptomatic HF after the point of diagnosis. HF patients are at high risk of sudden cardiac death from the early stages of the disease onwards. The decision of whether to perform cardiopulmonary resuscitation in the event of an emergency is challenging, especially in elderly HF patients, because of the difficulty in accurately predicting the prognosis of the condition. Furthermore, advanced HF patients are often fitted with a device, and device deactivation at the end of life is a complicated process. Treatment strategies should thus be discussed by multi-disciplinary teams, including palliative experts, and should consider patient directives to address the problems discussed above. Open communication with the HF patient regarding the expected prognosis, course, and treatment options will serve to support the patient and aid in future planning.

Keywords: Palliative care; End-of-life care; Heart failure; Aging; Aged

\section{INTRODUCTION}

\section{Population aging in Asia}

The development of advanced medical care techniques and life-saving procedures has greatly extended life expectancy. Currently, $8.5 \%$ of the world's population is over 60 years old, accounting for 617 million people, and this number is expected to increase more than threefold, to 2 billion, by 2050, while the global life expectancy is estimated to extend by 8.4 years, from 68.6 to 76.2 years $[1,2]$.

Notably, more than half of the world's aged population lives in Asia [2,3]. Japan has the oldest population, with $26.6 \%$ of its citizens aged over 65 years in 2016 , compared with only $13.1 \%$ in Korea $[4,5]$. However, the rate of population aging (i.e., the percentage of the population aged over 65 years) is expected to increase from $7 \%$ to $14 \%$ within 18 years in Korea, 20 years in Singapore, and 23 years in China [6]. Population aging is thus expected to advance more rapidly in other Asian countries compared with Japan, with the proportion of people aged over 60 in 2050 projected to reach $42.4 \%$ in Japan (1st in the world), $41.6 \%$ in Korea (4th), and $40.1 \%$ in Singapore (9th) (Fig. 1) [2].

\section{Heart failure pandemic in Asia}

The incidence of heart failure (HF) increases with age [7-9]. The number of HF patients has thus increased sharply, to an estimated total 26 million people worldwide, in line with the rapid increase in population aging 


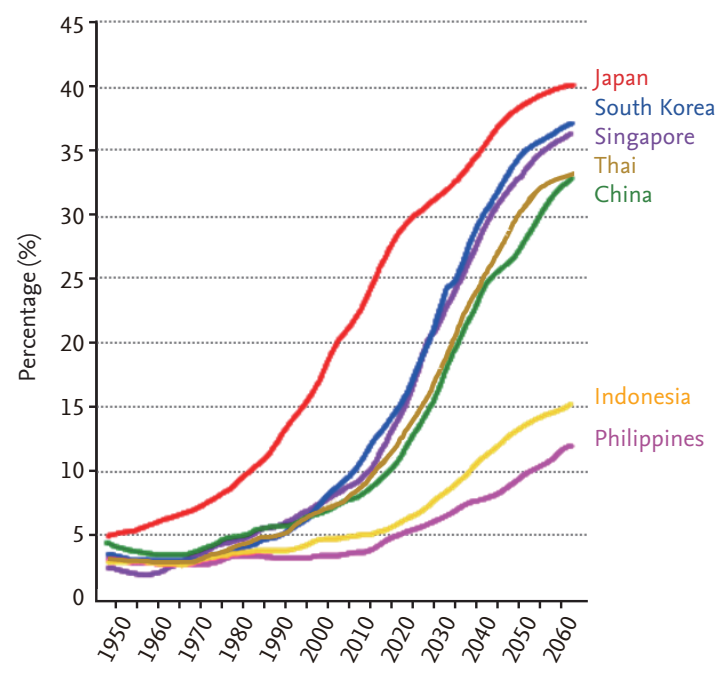

A

\begin{tabular}{|c|c|c|c|c|c|}
\hline \multicolumn{3}{|c|}{2017} & \multicolumn{3}{|c|}{2050} \\
\hline & Country, area & Percentage & & Country, area & Percentage \\
\hline 1 & Japan & 33.4 & 1 & Japan & 42.4 \\
\hline 2 & Italy & 29.4 & 2 & Spain & 41.9 \\
\hline 3 & Germany & 28.0 & 3 & Portugal & 41.7 \\
\hline 4 & Portugal & 27.9 & 4 & Greece & 41.6 \\
\hline 5 & Finland & 27.8 & 5 & South Korea & 41.6 \\
\hline 6 & Bulgaria & 27.7 & 6 & Taiwan & 41.3 \\
\hline 7 & Coatia & 26.8 & 7 & Hong Kong & 40.6 \\
\hline 8 & Greece & 26.5 & 8 & Italy & 40.3 \\
\hline 9 & Slovenia & 26.3 & 9 & Singapore & 40.1 \\
\hline 10 & Latvia & 26.2 & 10 & Poland & 39.5 \\
\hline
\end{tabular}

B

Figure 1. Population aging in Asia. (A) Annual trend of aging rate. Aging rate is defined as the percentage of population aged 65 or over. (B) Top 10 countries/areas with high percentage of population aged 60 or over. Asian countries/areas are highlighted in red.

$[10,11]$, including in Asia [3,12,13]. The number of HF outpatients in Japan was estimated at 979,000 in 2005 , and is predicted to increase gradually and reach 1.3 million by 2030 [14]. Similarly, the prevalence of HF in Korea was $0.75 \%$ in 2002 , and is expected to approximately double (1.53\%) by 2013 and then again (3.35\%) by $2040[15,16]$.

$\mathrm{HF}$ is a clinical syndrome caused by structural and/ or functional cardiac abnormalities, with shortness of breath on exertion or peripheral edema being the main symptom, often accompanied by a significant reduction in quality of life (QOL) [17,18]. Because HF stage advances with aging, deterioration of QOL becomes more marked and the intensity of care required thus increases [19-21]. The explosive increase in the number of HF patients in Asia in association with pronounced population aging is likely to impose a heavy burden, not only economically but also socially, including with respect to palliative and end-of-life care for patients with advanced HF [21-27].

\section{PALLIATIVE AND END-OF-LIFE CARE}

\section{Definitions of palliative and end-of-life care}

The World Health Organization defined palliative care as "an approach that improves the QOL of patients and their families facing the problem associated with life-threatening illness, through the prevention and relief of suffering by means of early identification and impeccable assessment and treatment of pain and other problems, physical, psychosocial and spiritual" [28]. Palliative care can thus be considered an intensive and comprehensive approach to the patient's physical, emotional, psychological, and mental care, providing support both to the patient and their caregivers [29].

End-of-life care refers to the support and medical care provided during the time near death [30]. However, the concept of end of life is complicated and definitions differ among reports [31]. A statement on end-stage cardiovascular care by the Japanese Circulation Society defined 'endstage' as refractory HF conditions despite maximal medical therapy (i.e., stage D) and 'end of life' as the phase of life in which a person is living with an illness that will worsen and eventually cause death [30,32-34]. Lamont introduced the concept of-life expectancy and considered the end-oflife period according to two perspectives: (1) a disease-centered perspective, in which the end-of-life period is one of irreversible decline before death, and (2) a time-based perspective related to the hospice admission criteria of a life expectancy of 6 months or less [35].

\section{When should palliative and end-of-life care be start- ed in HF patients?}

In recent years, numerous guidelines for palliative and end-of-life care have been recommended, based on ac- 
Table 1. Recommendation of palliative care in heart failure guidelines

\begin{tabular}{|c|c|c|c|}
\hline & $\begin{array}{c}\text { Class of } \\
\text { recommendation }\end{array}$ & Level of evidence & Recommendation \\
\hline \multirow[t]{2}{*}{$\begin{array}{l}2013 \text { ACCF/AHA Guideline } \\
\text { for the Management of } \\
\text { Heart Failure }\end{array}$} & Class I & B & $\begin{array}{l}\text { Throughout the hospitalization as appropriate, be- } \\
\text { fore hospital discharge, at the first postdischarge } \\
\text { visit, and in subsequent follow-up visits, the } \\
\text { following should be addressed: consideration for } \\
\text { palliative care or hospice care in selected patients. }\end{array}$ \\
\hline & Class I & B & $\begin{array}{l}\text { Palliative and supportive care is effective for pa- } \\
\text { tients with symptomatic advanced heart failure to } \\
\text { improve quality of life. }\end{array}$ \\
\hline \multirow[t]{2}{*}{$\begin{array}{l}\text { The } 2013 \text { International } \\
\text { Society for Heart and Lung } \\
\text { Transplantation Guidelines } \\
\text { for mechanical circulatory } \\
\text { support: executive summary }\end{array}$} & Class IIa & $\mathrm{C}$ & $\begin{array}{l}\text { Palliative care consultation should be a compo- } \\
\text { nent of the treatment of end-stage heart failure } \\
\text { during the evaluation phase for MCS. In addition } \\
\text { to symptom management, goals and preferences } \\
\text { for end of life should be discussed with patients } \\
\text { receiving MCS as DT. }\end{array}$ \\
\hline & Class I & $\mathrm{C}$ & $\begin{array}{l}\text { Consultation with palliative medicine should be } \\
\text { considered prior to MCS device implantation to } \\
\text { facilitate discussion of end-of-life issues and es- } \\
\text { tablish an advance directive or living will, particu- } \\
\text { larly when implanted as DT. }\end{array}$ \\
\hline $\begin{array}{l}2016 \text { ESC Guidelines for the } \\
\text { diagnosis and treatment } \\
\text { of acute and chronic heart } \\
\text { failure }\end{array}$ & Class I & A & $\begin{array}{l}\text { It is recommended that patients with HF are en- } \\
\text { rolled in a multidisciplinary care management } \\
\text { program to reduce the risk of HF hospitalization } \\
\text { and mortality. }\end{array}$ \\
\hline \multirow[t]{3}{*}{$\begin{array}{l}\text { Guidelines for Acute and } \\
\text { Chronic Heart Failure } \\
\text { (JCS2017/JHFS2017) }\end{array}$} & Class I & B & $\begin{array}{l}\text { Perform advanced care planning which is the } \\
\text { process of dialogue about medical treatment with } \\
\text { patients and families in advance before the ability } \\
\text { of decision-making is failed. }\end{array}$ \\
\hline & Class I & $\mathrm{C}$ & $\begin{array}{l}\text { Continue treatment for heart failure and compli- } \\
\text { cations and aim for palliation of coexisting symp- } \\
\text { toms. }\end{array}$ \\
\hline & Class II & $\mathrm{C}$ & $\begin{array}{l}\text { Frequent assessment of physical, psychological, and } \\
\text { spiritual needs of patients by multidisciplinary } \\
\text { team. }\end{array}$ \\
\hline
\end{tabular}

ACCF, American College of Cardiology Foundation; AHA, American Heart Association; MCS, mechanical circulatory support; DT, destination therapy; ESC, European Society of Cardiology; HF, heart failure; JCS, Japanese Circulation Society; JHFS, Japanese Heart Failure Society.

cumulated evidence (Table 1). The American College of Cardiology Foundation/American Heart Association HF guidelines recommend palliative and supportive care to improve QOL for advanced HF patients, and as a treatment goal for patients with refractory conditions classified as stage D $[33,36,37]$. Another study recommended use of a quality index for the early detection of candidate HF patients for palliative care [38]. Candidates should fulfil seven criteria of the index, including severe symptoms (classified as New York Heart Association [NYHA] functional class IV), frequent hospitalization (> 3 times a year), and a general deterioration in clinical condition (e.g., presence of edema, orthopnea, nycturia, or dyspnea). A previous study concluded that HF patients should be considered as candidates for palliative care if a physician answered "no" to the question of "Would I be surprised 


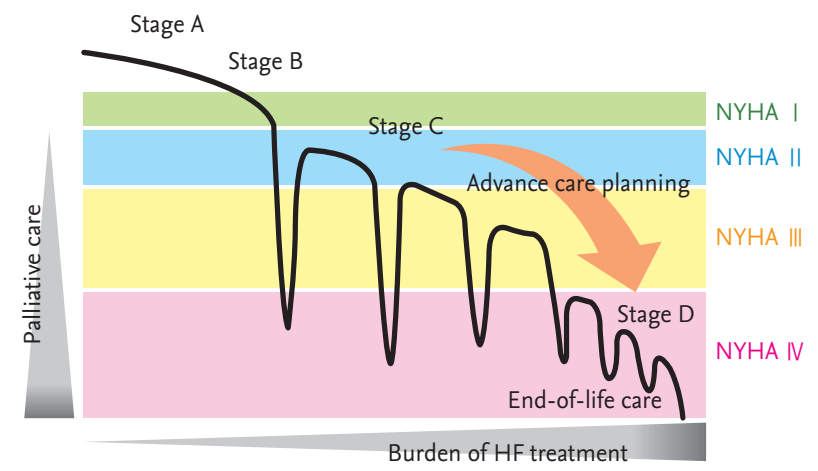

Figure 2. Palliative and end-of-life care in the time course of heart failure. NYHA, New York Heart Association; HF, heart failure.

if my patient were to die in the next 12 months?" [39]. Many treatments for HF can be considered as care leading to symptomatic relief. For instance, diuretic treatment for pulmonary congestion improves dyspnea in HF patients and thus alleviates the fear of death. Palliative care can therefore be provided at any stage of symptomatic HF after diagnosis to minimize suffering, in terms of physical pain and mental, social, and spiritual distress $[20,22,40]$.

The European Society of Cardiology HF guidelines recommend that end-of-life care should be considered for patients meeting the following criteria: (1) progressive functional decline (physical and mental) and dependence in most activities of daily living; (2) severe HF symptoms with poor QOL despite optimal pharmacological and non-pharmacological therapies; (3) frequent admissions to hospital or other serious episodes of decompensation despite optimal treatment; (4) heart transplantation and mechanical circulatory support ruled out; (5) cardiac cachexia; and (6) clinically judged to be close to the end of life [17].

As noted above, palliative and end-of-life care are not identical concepts. Unfortunately, a structured qualitative interview of medical professionals, including doctors, revealed that care providers had limited comprehension regarding how palliative care could complement medical therapies and the value of palliative care for HF patients and care teams [41]. In addition, many medical professionals mistakenly believed that palliative care should only be provided to end-of-life patients facing death. End-of-life care is actually a specific type of palliative care provided for patients with an expected lifespan of $<6$ months, designed to maintain daily QOL, avoid repeated hospitalization, and achieve a happy end of life, according to each patient's wishes [40]. However, it is difficult to predict the mortality of HF patients accurately $[42,43]$, and this prognostic uncertainty makes it difficult to plan towards fulfilling the patient's endof- life wishes. Palliative care should aim to meet the patient's needs regardless of their prognosis (Fig. 2) [44,45].

\section{MANAGEMENT OF PALLIATIVE CARE FOR HF}

The World Health Organization estimates that 39\% of the 40 million people with cardiovascular disease worldwide require palliative care on a yearly basis [46], but unfortunately $86 \%$ of them do not receive this care. It is necessary to properly address the various symptoms that manifest in HF (Table 2).

\section{Dyspnea}

Dyspnea is one of the main features of congestive HF. The initial management of dyspnea in HF patients includes standard treatment with diuretics, vasodilators, and positive inotropic drugs as necessary. Thoracic puncture may be performed for refractory pleural effusion, while oral or intravenous morphine may alleviate symptoms in patients with refractory dyspnea. However, most patients dying of HF are less likely to be alleviated using opioids due to repulsion [47]. Adaptive servo-ventilation therapy was recently reported to have a negative effect on prognosis among HF patients with reduced ejection fraction [48], while oxygen therapy and appropriate positive pressure ventilation may be useful for symptomatic relief in some cases [49].

\section{Pain}

Pain has been reported in up to $89 \%$ of HF patients classified as NYHA functional class IV [50]. In addition, moderate to severe pain was noted in $41 \%$ of patients dying of HF during their final 3 days, with overall pain reported in approximately $80 \%$ of patients dying of HF [51]. Similar to the symptomatic relief of dyspnea, lowdose opioids may help control pain in this population. Nonsteroidal anti-inflammatory agents are not recommended because they tend to cause sodium retention, gastrointestinal bleeding, or deterioration of renal function [52]. 
Table 2. Clinical symptom and palliative management in heart failure

\begin{tabular}{|c|c|c|}
\hline Symptom & Rate, \% & Management \\
\hline Dyspnea & $60-88$ & $\begin{array}{l}\text { Solving reversible causes: pulmonary congestion, pleural effusion, } \\
\text { pneumonia, etc. } \\
\text { Rehabilitation, physical therapy, oxygen therapy } \\
\text { Opioids } \\
\text { Oral morphine } 2.5-5.0 \text { mg every } 4 \text { hours } \\
\text { Low dose intravenous diamorphine } 1-2 \mathrm{mg}\end{array}$ \\
\hline Pain & $41-89$ & $\begin{array}{l}\text { Rehabilitation, physical therapy, oxygen therapy } \\
\text { Refer to WHO analgesic ladder } \\
\text { Acetaminophen } \\
\text { Opioids } \\
\text { Avoid NSAIDs/TCAs }\end{array}$ \\
\hline Fatigue & $69-82$ & $\begin{array}{l}\text { Solving reversible causes: hypothyroidism, depression, anemia, etc. } \\
\text { Rehabilitation, physical therapy } \\
\text { Consider decreased } \beta \text {-blocking agent }\end{array}$ \\
\hline Anxiety depression & $\begin{array}{c}49 \\
10-60\end{array}$ & $\begin{array}{l}\text { Treatment for physical and existential pain } \\
\text { Antidepressant } \\
\text { SSRI } \\
\text { Mirtazapine } \\
\text { Avoid TCAs/SNRIs }\end{array}$ \\
\hline Nausea/Vomitting & $17-48$ & $\begin{array}{l}\text { Solving reversible causes: gastrointestinal edema, side effect of drug, etc. } \\
\text { Metclopramide } \\
\text { Low-dose haloperidol }\end{array}$ \\
\hline
\end{tabular}

WHO, World Health Organization; NSAID, nonsteroidal anti-inflammatory drug; TCA, tricyclic antidepressant; SSRI, selective serotonin reuptake inhibitor; SNRI, serotonin-norepinephrine reuptake inhibitor.

\section{Fatigue}

General fatigue may result from decreased cardiac output, and positive inotropic agents may provide symptomatic relief. Continuous intravenous administration of inotropes has been associated with a reduced need for hospitalization in cases of worsening HF, but could increase mortality [53]. Furthermore, fatigue may be related to depression, which co-exists with HF in many patients. However, the efficacy of selective serotonin reuptake inhibitors for treating depression in HF patients has not been established [54].

\section{Psychosocial and spiritual problems}

Patients with advanced HF often suffer from psychosocial and spiritual problems, characterized by hopelessness, isolation, and altered self-image [55]. They may have anxiety over issues such as the meaning of life, their physical needs, their family and social life, loss of dignity, increased dependence, and a desire to die [56]. To address these problems, it is necessary to discuss subjects such as life goals and life closure, illness and attendant suffering, coping ability, etc., with both the patients and their caregivers [57].

\section{END-OF-LIFE CARE FOR PATIENTS WITH DEVICE THERAPY}

\section{Implantable cardioverter-defibrillator}

Patients with HF at high risk of sudden cardiac death (SCD) due to ventricular arrhythmia may be fitted with an implantable cardioverter-defibrillator (ICD) [58]. Recent guidelines recommend this option in patients with a life expectancy of $>1$ year $[17,59]$. However, ICDs are more likely to cause serious distress and anxiety in patients with advanced HF due to frequent shocking [60,61], and ICD deactivation is therefore a recommended treatment option during end-of-life care in patients with stage D HF.

Although most clinicians understand the need to consider ICD deactivation, many are reluctant to dis- 
cuss this issue with their patients; indeed, in one study, only $25 \%$ of patients' families discussed switching off their ICD device with the physician before the patient died [62]. Unfortunately, even in patients who had previously expressed a wish to restrict life-prolonging therapy, ICD deactivation was only discussed near the end of life. Clinicians thus need to discuss device deactivation with end-stage HF patients at an earlier and more appropriate stage.

\section{Ventricular assist devices}

Patients with advanced HF who are not eligible for heart transplantation may be suitable for an implantable artificial heart (ventricular assist device [VAD]). The 48-month survival rate of patients with a VAD is $49 \%$ in the United States, while it is especially high (88.7\%) in Japan $[63,64]$. However, VAD implantation involves invasive thoracotomy and hospitalization, which are associated with a high risk of complications such as stroke and infection $[65,66]$, especially in older patients [67]. Furthermore, although a VAD can relieve HF symptoms, such as shortness of breath and dyspnea, and improve exercise capacity, patients may continue to experience other symptoms such as physical pain, depression, and anxiety [68].

VADs also involve extensive commitment from the patient's caregivers, who are required to provide 24-hour support for an indefinite period after VAD transplantation. Further research is needed to establish an effective strategy to reduce this burden on caregivers [22].

VAD implantation should only be performed after extensive discussion among medical professionals, patients, and their caregivers. Ideally, the VAD care team should also include palliative specialists to assist with pre- and post-operative pain or symptom management, and support the transition to end-of-life care if necessary.

\section{ISSUES WITH PALLIATIVE AND END-OF-LIFE CARE IN THE ELDERLY}

Most hospitalized patients with worsening HF are elderly, with an average age of patients in the REALITY-AHF (Registry Focused on Very Early Presentation and Treatment in Emergency Department of Acute Heart Failure) registry in Japan of 78 years [69]. Palliative care for the elderly is generally considered to be difficult [70] for several reasons. First, elderly patients may have difficulty conveying their symptoms accurately and it may be hard for physicians to evaluate their pain. In addition, elderly patients are also more likely to have various comorbidities and to be receiving multiple drugs, and at high doses. Finally, the patient's individual circumstances have a major influence on the choice of treatment strategy, and it is necessary to involve caregivers in this discussion.

The end-of-life process in elderly patients is also more diverse and complicated than in younger adults [71], and views of life and death among the elderly vary. Contrary to expectations, most elderly patients in one study opted for longevity above QOL, and half wanted to be resuscitated as necessary [72]. However, such patients feel close to death for the remainder of their life and thus tend to explore the meaning of life. Most elderly patients with HF are prepared to confront their terminal condition, and although their wishes in terms of end-of-life care may change due to various factors, such as their degree of cognitive function and their surrounding environment, the desire for a tranquil death remains constant [73].

\section{CARDIOPULMONARY RESUSCITATION}

SCD can occur not only in patients with advanced HF, but also in those with early-stage HF [74]. SCD is the predominant cause of death in patients with less-symptomatic or less-severe HF, whereas progressive HF with hypotension, hypoperfusion, or metabolic disturbance is a more common cause of death among patients with advanced $\mathrm{HF}[75,76]$. It is therefore important for all HF patients to consider, in advance, what treatment they would/would not like to receive if cardiopulmonary resuscitation is needed [77,78].

Physician Orders for Life-Sustaining Treatment (POLST) is a concept advocated in the United States based on practical experience of advance directives, and includes the do-not-attempt-resuscitation (DNAR) directive, which precludes cardiopulmonary resuscitation in the event of cardiac arrest $[78,79]$. Numerous POLSTlike programs, such as Medical Orders for Life-Sustaining Treatment (MOLST), Medical Orders for Scope of Treatment (MOST), Transportable Physician Orders 
for Patient Preferences (TPOPP), Iowa Physician Order for Scope of Treatment (IPOST), Louisiana Physician Orders for Scope of Treatment (LaPOST), and Physician Order for Scope of Treatment (POST), have since been proposed and used in various parts of the United States. In contrast, the infrastructure required to ensure smooth operation of POLST has not been established in Japan, and the Ethics Committee of the Japanese Society of Intensive Care Medicine decided not to introduce POLST into acute care, concluding that correct understanding and application of DNAR should be given priority [8o].

\section{COMMUNICATION AND PLANNING FOR END OF LIFE}

\section{Advance care planning}

As noted above, it is difficult to accurately predict the prognosis of HF. In addition, approximately $70 \%$ of patients lack decision-making capacity at the end of life [81]. It is therefore necessary for the expected prognosis to be reviewed repeatedly and discussed among medical professionals, patients, and their caregivers to ensure that the patient's philosophy and goals in life are respected [82]. Advance care planning (ACP) is a voluntary process involving discussion about future care between an individual and their care providers, irrespective of discipline [83]. The goal of ACP is to help ensure that people receive medical care that is consistent with their values, goals, and preferences during serious and chronic illness [84]. The patient's intentions with respect to ACP may be conveyed via a written advance directive in case of emergencies; however, in many patients with $\mathrm{HF}$ discussion of their ACP will be delayed until the terminal stage $[85,86]$. In addition, human emotions and intentions can fluctuate greatly, and medical professionals and caregivers are expected to guide the patient to make the best decisions at all stages of HF.

\section{Palliative and end-of-life care team approach for HF}

End-of-life care includes not only symptomatic care but also hospice care, advanced instructions, and ACP [32]. To address these complicated issues, it is discussion is necessary among a team that includes cardiovascular physicians, palliative medical doctors, psychiatrists, nurses, psychologists, patients, and their caregivers. In many cases, palliative care teams may have extensive experience in caring for cancer patients but limited experience with HF patients. In addition, cardiologists and HF specialists often do not feel comfortable and/ or have not been trained to address the challenges associated with terminal care, while general physicians, geriatric physicians, and other clinicians with expertise in palliative care lack knowledge and expertise regarding HF management $[32,87,88]$. Furthermore, the patients themselves may not appreciate the life-limiting nature of $\mathrm{HF}$ and their prognosis presents an additional barrier to planning end-of-life care [89]. Maintaining open channels of communication about the anticipated prognosis, course, and treatment possibilities of HF is thus crucial to allow patients to plan for their future [9o]. Furthermore, a team familiar with palliative care should be established early during the treatment of HF patients.

\section{CONCLUSIONS}

Given the aging population in Asia, palliative and endof-life care for elderly patients with HF is expected to become an even greater issue in the future. Withholding or discontinuing medical treatments during end-of-life care should be discussed by multidisciplinary teams, including palliative specialists, with consideration of the individual patient's directives. Open communication with the HF patient regarding their expected prognosis, course, and treatment options will serve to comfort the patient and aid in planning future treatment.

\section{Conflict of interest}

No potential conflict of interest relevant to this article was reported.

\section{REFERENCES}

1. Yasobant S. Comprehensive public health action for our aging world: the quintessence of public health policy. $J$ Int Med Res 2018;46:555-556.

2. United Nations, Department of Economic and Social Affairs, Population Division. World population prospects: the 2017 revision [Internet]. New York: United Nations, 
2017 [cited 2018 Mar 22]. Available from: https://esa.un.org/unpd/wpp/.

3. Shimokawa H, Miura M, Nochioka K, Sakata Y. Heart failure as a general pandemic in Asia. Eur J Heart Fail 2015; 17:884-892.

4. Cabinet office, Government of Japan. Annual report on the aging society: 2016 (summary) [Internet]. Tokyo (JP): Cabinet office, Government of Japan, c2014 [cited 2018 Mar 22]. Available from: http://www8.cao.go.jp/kourei/english/annualreport/2016/pdf/c1-1.pdf.

5. United Nations, Department of Economic and Social Affairs, Population Division. World population prospects: the 2015 revision [Internet]. New York: United Nations, 2017 [cited 2018 Mar 22]. Available from: https://esa.un.org/unpd/wpp/.

6. National Institute of Population and Social Security Research. Latest Demographic Statistics 2016. Population Research Series. Tokyo (JP): National Institute of Population and Social Security Research, 2016.

7. Christiansen MN, Kober L, Weeke P, et al. Age-specific trends in incidence, mortality, and comorbidities of heart failure in Denmark, 1995 to 2012. Circulation 2017;135:12141223 .

8. Dharmarajan K, Rich MW. Epidemiology, pathophysiology, and prognosis of heart failure in older adults. Heart Fail Clin 2017;13:417-426.

9. Rajadurai J, Tse HF, Wang CH, Yang NI, Zhou J, Sim D. Understanding the epidemiology of heart failure to improve management practices: an Asia-Pacific perspective. J Card Fail 2017;23:327-339.

10. Ambrosy AP, Fonarow GC, Butler J, et al. The global health and economic burden of hospitalizations for heart failure: lessons learned from hospitalized heart failure registries. J Am Coll Cardiol 2014;63:1123-1133.

11. Lloyd-Jones DM, Larson MG, Leip EP, et al. Lifetime risk for developing congestive heart failure: the Framingham Heart Study. Circulation 2002;106:3068-3072.

12. Sakata Y, Shimokawa H. Epidemiology of heart failure in Asia. Circ J 2013;77:2209-2217.

13. Sato N. Epidemiology of heart failure in Asia. Heart Fail Clin 2015;11:573-579.

14. Okura Y, Ramadan MM, Ohno Y, et al. Impending epidemic: future projection of heart failure in Japan to the year 2055. Circ J 2008;72:489-491.

15. Lee JH, Lim NK, Cho MC, Park HY. Epidemiology of heart failure in Korea: present and future. Korean Circ J
2016;46:658-664.

16. Park JJ, Choi DJ. Heart failure epidemic: an expected phenomenon. Korean Circ J 2016;46:610-612.

17. Ponikowski P, Voors AA, Anker SD, et al. 2016 ESC guidelines for the diagnosis and treatment of acute and chronic heart failure: the task force for the diagnosis and treatment of acute and chronic heart failure of the European Society of Cardiology (ESC) developed with the special contribution of the Heart Failure Association (HFA) of the ESC. Eur Heart J 2016;37:2129-2200.

18. Lim SL, Lam CS. Breakthrough in heart failure with preserved ejection fraction: are we there yet? Korean J Intern Med 2016;31:1-14.

19. Allen LA, Stevenson LW, Grady KL, et al. Decision making in advanced heart failure: a scientific statement from the American Heart Association. Circulation 2012;125:19281952.

20. McIlvennan CK, Allen LA. Palliative care in patients with heart failure. BMJ 2016;353:11010.

21. Lanken PN, Terry PB, Delisser HM, et al. An official American Thoracic Society clinical policy statement: palliative care for patients with respiratory diseases and critical illnesses. Am J Respir Crit Care Med 2008;177:912-927.

22. Ghashghaei R, Yousefzai R, Adler E. Palliative care in heart failure. Prog Cardiovasc Dis 2016;58:455-460.

23. Yumino D. Home medical care for heart failure. Yakugaku Zasshi 2016;136:1133-1136.

24. Wordingham SE, McIlvennan CK, Dionne-Odom JN, Swetz KM. Complex care options for patients with advanced heart failure approaching end of life. Curr Heart Fail Rep 2016;13:20-29.

25. Mizuno A, Miyashita M, Hayashi A, et al. Potential palliative care quality indicators in heart disease patients: a review of the literature. J Cardiol 2017;70:335-341.

26. Lee H, Oh SH, Cho H, Cho HJ, Kang HY. Prevalence and socio-economic burden of heart failure in an aging society of South Korea. BMC Cardiovasc Disord 2016;16:215.

27. Sato Y. Multidisciplinary management of heart failure just beginning in Japan. J Cardiol 2015;66:181-188.

28. World Health Organization. The World Health Report 2002: Reducing Risks, Promoting Healthy Life. Geneva: World Health Organization, 2002.

29. Chen-Scarabelli C, Saravolatz L, Hirsh B, Agrawal P, Scarabelli TM. Dilemmas in end-stage heart failure. J Geriatr Cardiol 2015;12:57-65.

30. Qaseem A, Snow V, Shekelle P, et al. Evidence-based inter 
ventions to improve the palliative care of pain, dyspnea, and depression at the end of life: a clinical practice guideline from the American College of Physicians. Ann Intern Med 2008;148:141-146.

31. Hui D, Nooruddin Z, Didwaniya N, et al. Concepts and definitions for "actively dying," "end of life," "terminally ill," "terminal care," and "transition of care": a systematic review. J Pain Symptom Manage 2014;47:77-89.

32. Goodlin SJ. End-of-life care in heart failure. Curr Cardiol Rep 2009;11:184-191.

33. Hunt SA, Abraham WT, Chin MH, et al. 2009 Focused update incorporated into the ACC/AHA 2005 guidelines for the diagnosis and management of heart failure in adults a report of the American College of Cardiology Foundation/ American Heart Association task force on practice guidelines developed in collaboration with the International Society for Heart and Lung Transplantation. J Am Coll Cardiol 2009;53:e1-e9o.

34. Japanese Circulation Society. Statement for end-stage cardiovascular care (JCS 2010) [Internet]. Tokyo (JP): Japanese Circulation Society, 2010 [cited 2018 Mar 22]. Available from: http://www.j-circ.or.jp/guideline/pdf/JCS2O1O_ nonogi_ h.pdf. Japanese.

35. Lamont EB. A demographic and prognostic approach to defining the end of life. J Palliat Med 2005;8 Suppl 1:S12-S21.

36. Yancy CW, Jessup M, Bozkurt B, et al. 2013 ACCF/AHA guideline for the management of heart failure: executive summary: a report of the American College of Cardiology Foundation/American Heart Association task force on practice guidelines. Circulation 2013;128:1810-1852.

37. Fang JC, Ewald GA, Allen LA, et al. Advanced (stage D) heart failure: a statement from the Heart Failure Society of America Guidelines Committee. J Card Fail 2015;21:519534 .

38. Thoonsen B, Engels Y, van Rijswijk E, et al. Early identification of palliative care patients in general practice: development of RADboud indicators for PAlliative Care Needs (RADPAC). Br J Gen Pract 2012;62:e625-e631.

39. Murray SA, Boyd K, Sheikh A. Palliative care in chronic illness. BMJ 2005;330:611-612.

40. Psotka MA, McKee KY, Liu AY, Elia G, De Marco T. Palliative care in heart failure: what triggers specialist consultation? Prog Cardiovasc Dis 2017;60:215-225.

41. Kavalieratos D, Mitchell EM, Carey TS, et al. "Not the 'grim reaper service'": an assessment of provider knowledge, at- titudes, and perceptions regarding palliative care referral barriers in heart failure. J Am Heart Assoc 2014;3:e0o0544.

42. Huynh BC, Rovner A, Rich MW. Long-term survival in elderly patients hospitalized for heart failure: 14-year follow-up from a prospective randomized trial. Arch Intern Med 2006;166:1892-1898.

43. Huynh BC, Rovner A, Rich MW. Identification of older patients with heart failure who may be candidates for hospice care: development of a simple four-item risk score. J Am Geriatr Soc 2008;56:1111-1115.

44. Morrison RS, Meier DE. Clinical practice. Palliative care. N Engl J Med 2004;350:2582-2590.

45. World Health Organization. Palliative care fact sheet 2017 [Internet]. Geneva: World Health Organization, c2018 [cited 2018 Mar 22]. Available from: http://www.who.int/mediacentre/factsheets/fs402/en/.

46. Connor SR, Bermedo MCS; Worldwide Palliative Care Alliance; World Health Organization. Global Atlas of Palliative Care at the End of Life. London: Worldwide Palliative Care Alliance, 2014.

47. Setoguchi S, Glynn RJ, Stedman M, Flavell CM, Levin R, Stevenson LW. Hospice, opiates, and acute care service use among the elderly before death from heart failure or cancer. Am Heart J 2010;160:139-144.

48. Cowie MR, Woehrle H, Wegscheider K, et al. Adaptive servo-ventilation for central sleep apnea in systolic heart failure. N Engl J Med 2015;373:1095-1105.

49. Momomura S, Seino Y, Kihara Y, et al. Adaptive servo-ventilation therapy for patients with chronic heart failure in a confirmatory, multicenter, randomized, controlled study. Circ J 2015;79:981-990.

50. Levenson JW, McCarthy EP, Lynn J, Davis RB, Phillips RS. The last six months of life for patients with congestive heart failure. J Am Geriatr Soc 2000;48(5 Suppl):S101-S109.

51. Evangelista LS, Sackett E, Dracup K. Pain and heart failure: unrecognized and untreated. Eur J Cardiovasc Nurs 2009;8:169-173.

52. Bleumink GS, Feenstra J, Sturkenboom MC, Stricker BH. Nonsteroidal anti-inflammatory drugs and heart failure. Drugs 2003;63:525-534.

53. Hauptman PJ, Mikolajczak P, George A, et al. Chronic inotropic therapy in end-stage heart failure. Am Heart J 2006;152:1096.

54. O'Connor CM, Jiang W, Kuchibhatla M, et al. Safety and efficacy of sertraline for depression in patients with heart failure: results of the SADHART-CHF (Sertraline Against 
Depression and Heart Disease in Chronic Heart Failure) trial. J Am Coll Cardiol 2010;56:692-699.

55. Nicholas Dionne-Odom J, Hooker SA, Bekelman D, et al. Family caregiving for persons with heart failure at the intersection of heart failure and palliative care: a state-ofthe-science review. Heart Fail Rev 2017;22:543-557.

56. McClung JA. End-of-life care in the treatment of heart failure in older adults. Heart Fail Clin 2017;13:633-644.

57. Bekelman DB, Hutt E, Masoudi FA, Kutner JS, Rumsfeld JS. Defining the role of palliative care in older adults with heart failure. Int J Cardiol 2008;125:183-190.

58. Yokoshiki H, Shimizu A, Mitsuhashi T, et al. Survival and heart failure hospitalization in patients with cardiac resynchronization therapy with or without a defibrillator for primary prevention in Japan: analysis of the Japan Cardiac Device Treatment Registry Database. Circ J 2017;81:17981806.

59. Yancy CW, Jessup M, Bozkurt B, et al. 2017 ACC/AHA/ HFSA focused update of the 2013 ACCF/AHA guideline for the management of heart failure: a report of the American College of Cardiology/American Heart Association task force on clinical practice guidelines and the Heart Failure Society of America. Circulation 2017;136:e137-e161.

6o. Pettit SJ, Browne S, Hogg KJ, et al. ICDs in end-stage heart failure. BMJ Support Palliat Care 2012;2:94-97.

61. Park KH, Lee CH, Jung BC, et al. Effectiveness of implantable cardioverter-defibrillator therapy for heart failure patients according to ischemic or non-ischemic etiology in Korea. Korean Circ J 2017;47:72-81.

62. Goldstein NE, Lampert R, Bradley E, Lynn J, Krumholz HM. Management of implantable cardioverter defibrillators in end-of-life care. Ann Intern Med 2004;141:835-838.

63. Kirklin JK, Pagani FD, Kormos RL, et al. Eighth annual INTERMACS report: special focus on framing the impact of adverse events. J Heart Lung Transplant 2017;36:10801086.

64. Nakatani T, Sase K, Oshiyama H, et al. Japanese registry for mechanically assisted circulatory support: first report. J Heart Lung Transplant 2017;36:1087-1096.

65. Yoshioka D, Toda K, Ono M, et al. Clinical results, adverse events, and change in end-organ function in elderly patients with HeartMateII left ventricular assist device: Japanese multicenter study. Circ J 2018;82:409-418.

66. Starling RC, Estep JD, Horstmanshof DA, et al. Risk assessment and comparative effectiveness of left ventricular assist device and medical management in ambulatory heart failure patients: the ROADMAP study 2-year results. JACC Heart Fail 2017;5:518-527.

67. Huang R, Deng M, Rogers JG, et al. Effect of age on outcomes after left ventricular assist device placement. Transplant Proc 2006;38:1496-1498.

68. Shapiro PA, Levin HR, Oz MC. Left ventricular assist devices. Psychosocial burden and implications for heart transplant programs. Gen Hosp Psychiatry 1996;18(6 Suppl): $30 \mathrm{~S}-35 \mathrm{~S}$.

69. Matsue Y, Damman K, Voors AA, et al. Time-to-furosemide treatment and mortality in patients hospitalized with acute heart failure. J Am Coll Cardiol 2017;69:30423051.

70. Ladha A, Sharma S, Batsis JA, Hanson GA, Swetz KM. Care of the frail elder: the nexus of geriatrics and palliative care. Minn Med 2013;96:39-42.

71. Gill TM, Gahbauer EA, Han L, Allore HG. Trajectories of disability in the last year of life. N Engl J Med 2010; 362:1173-1180.

72. Brunner-La Rocca HP, Rickenbacher P, Muzzarelli S, et al. End-of-life preferences of elderly patients with chronic heart failure. Eur Heart J 2012;33:752-759.

73. Hattori A, Matsuda Y, Fetters MD, et al. A quantitative exploration of elderly patients' preferences for end-of-life care. Japan Med Assoc J 2005;48:388-397.

74. Carson P, Anand I, O'Connor C, et al. Mode of death in advanced heart failure: the Comparison of Medical, Pacing, and Defibrillation Therapies in Heart Failure (COMPANION) trial. J Am Coll Cardiol 2005;46:2329-2334.

75. Teuteberg JJ, Lewis EF, Nohria A, et al. Characteristics of patients who die with heart failure and a low ejection fraction in the new millennium. J Card Fail 2006;12:47-53.

76. Derfler MC, Jacob M, Wolf RE, Bleyer F, Hauptman PJ. Mode of death from congestive heart failure: implications for clinical management. Am J Geriatr Cardiol 2004;13:299-304.

77. Butterworth AM. Advance directives. Vital to quality care for elderly patients. Adv Nurse Pract 2004;12:69-75.

78. Pope TM, Hexum M. Legal briefing: POLST: physician orders for life-sustaining treatment. J Clin Ethics 2012;23:353-376.

79. Guidelines for emergency physicians on the interpretation of physician orders for life-sustaining therapy (POLST). Ann Emerg Med 2017;70:122-125.

8o. Ethics Committee, Japanese Society of Intensive Care Medicine. Physician orders for life-sustaining treatment 
(POLST) and do not attempt resuscitation (DNAR) order. J Japan Soc Intensive Care Med 2017;24:216-226.

81. Silveira MJ, Kim SY, Langa KM. Advance directives and outcomes of surrogate decision making before death. $\mathrm{N}$ Engl J Med 2010;362:1211-1218.

82. Brinkman-Stoppelenburg A, Rietjens JA, van der Heide A. The effects of advance care planning on end-of-life care: a systematic review. Palliat Med 2014;28:1000-1025.

83. End of Life Care Programme. Advance care planning: a guide for health and social care staff [Internet]. Leicester (UK): National Council for Palliative Care, c2015 [cited 2018 Mar 22]. Available from: http://www.ncpc.org.uk/ sites/default/files/AdvanceCarePlanning.pdf.

84. Sudore RL, Lum HD, You JJ, et al. Defining advance care planning for adults: a consensus definition from a multidisciplinary Delphi panel. J Pain Symptom Manage 2017;53:821-832.

85. Murray SA, Boyd K, Kendall M, Worth A, Benton TF, Clausen $\mathrm{H}$. Dying of lung cancer or cardiac failure: prospective qualitative interview study of patients and their carers in the community. BMJ 2002;325:929.
86. Kim J, Kim S, Shin MS, Jin JO, Kim Y, Lee MO. A context-oriented communication algorithm for advance care planning: a model to assist palliative care in heart failure. J Cardiovasc Nurs 2018;33:446-452.

87. Goodlin SJ, Trupp R, Bernhardt P, Grady KL, Dracup K. Development and evaluation of the "Advanced Heart Failure Clinical Competence Survey": a tool to assess knowledge of heart failure care and self-assessed competence. Patient Educ Couns 2007;67:3-10.

88. Hauptman PJ, Swindle J, Hussain Z, Biener L, Burroughs TE. Physician attitudes toward end-stage heart failure: a national survey. Am J Med 2008;121:127-135.

89. Allen LA, Yager JE, Funk MJ, et al. Discordance between patient-predicted and model-predicted life expectancy among ambulatory patients with heart failure. JAMA 2008;299:2533-2542.

90. Murray SA, Kendall M, Grant E, Boyd K, Barclay S, Sheikh A. Patterns of social, psychological, and spiritual decline toward the end of life in lung cancer and heart failure. J Pain Symptom Manage 2007;34:393-402. 